\title{
As Jornadas de Junho no Brasil e a questão de gênero: as idas e vindas das lutas por justiça ${ }^{4}$
}

The Brazilian 2013 protests and the issue of gender

Estupro, agressões física e verbal, invisibilização da voz, assédio em revistas policiais, reprodução de estereótipos, marginalização de lideranças femininas: são muitos os episódios de violência de gênero a atravessar, de formas distintas e com diferentes pesos, o processo político das chamadas Jornadas de Junho de 2013 no Brasil. Paralelamente, entretanto, também há relatos sobre tentativas de tematização dessas práticas violentas no próprio cerne das manifestações. De denúncias a expulsões de coletivos, passando pela construção de Frentes Feministas, muitas mulheres contribuíram para questionar práticas opressivas que reproduzem a dominação masculina.

\footnotetext{
1 É doutora em Ciência Política pela Universidade Federal de Minas Gerais (UFMG). Pesquisadora do Margem, Grupo de Pesquisa em Democracia e Justiça desta instituição. E-mail: <yzasarmento@gmail.com>.

2 É mestranda em Ciência Política pela UFMG. Bolsista da Fapemig. E-mail: <slgreis92@gmail.com>.

3 É professor no Departamento de Ciência Política da UFMG. Doutor em Comunicação pela mesma instituição. Bolsista de produtividade do Conselho Nacional de Desenvolvimento Científico e Tecnológico (CNPq).E-mail: <ricardofabrino@hotmail.com>.

4 Versões preliminares deste texto foram apresentadas no VIII Congresso da Asociación Latinoamericana de Ciencia Política (Alacip) - Pontificia Universidad Católica del Perú (PUCP), Lima, Peru, 22 a 24 de julho de 2015 - e no VI Congresso da Associação Brasileira de Pesquisadores em Comunicação e Política (Compolítica) - Pontifícia Universidade Católica do Rio de Janeiro (PUC-Rio), Rio de Janeiro, 22 a 24 de abril de 2015. Este artigo foi elaborado no interior de um projeto de pesquisa financiado pelo CNPq (Processos 445955/2014-7 e 305117/2014-9), pela Fapemig (CSA-APQ-01206-15), pela Capes (Processo 88881.130844/2016-01) e pela Pró-Reitoria de Pesquisa (PRPq) da UFMG. A essas instâncias de fomento, somos gratos. Também somos gratos a Márcia Maria Cruz, a Selene Gomes de Oliveira Machado, a Davi Figueiredo de Sousa e a Renato Duarte Caetano pelo apoio na coleta e sistematização dos dados. A Márcio Bustamante e a Selen Ercan, manifestamos gratidão pelo suporte mais amplo no projeto.
} 
Este artigo pretende discutir essa tensa dinâmica de gênero no processo desdobrado das manifestações de 2013. Interessa-nos evidenciar a ambivalência desse momento de confronto político, já que ele é palco da reprodução de uma desigualdade estrutural, ao mesmo tempo em que joga luz sobre facetas desta desigualdade e possibilita seu questionamento reflexivo. Para tanto, levantamos, dentro de coletivos atravessados por tal processo, conflitos e tensões de gênero, bem como as estratégias adotadas para o enfrentamento destes. Ao fazê-lo, o texto evidencia a existência de opressão dentro de grupos tidos como emancipatórios, mas assinala o modo como o desrespeito instiga atores a repensarem-se ao longo de suas práticas.

Este trabalho está assentado em três matrizes teóricas. Em primeiro lugar, a discussão das teorias dos movimentos sociais oferecerá insumos para a compreensão da configuração processual e ambivalente de conflitos políticos. Em segundo lugar, a teoria do reconhecimento alimentará a discussão sobre os fundamentos morais das lutas políticas na transformação das gramáticas sociais e a dimensão paradoxal de certos avanços conquistados. Em terceiro lugar, a leitura feminista sobre o conceito de autonomia permitirá refletir sobre o potencial pedagógico das próprias lutas e o esforço de mulheres por se fazerem protagonistas em contextos de luta. Neste ponto, interessa-nos ressaltar que estamos plenamente cientes de que as três matrizes teóricas sobre as quais se assenta nosso olhar são atravessadas por muitos atritos em termos de premissas e implicações. Nossa proposta não almeja escamotear tais atritos ou resolvê-los. Nosso esforço é simplesmente o de mobilizar tais abordagens, desde seus devidos lugares, para construir um argumento sobre a natureza dinâmica e processual das lutas por justiça, entendendo que tais abordagens têm-se mostrado frutíferas para a compreensão de conflitos políticos.

Empiricamente, este artigo está assentado em dados gerados na pesquisa Protestos e Engajamento Político, que analisa as manifestações de 2013 nos municípios de São Paulo e de Belo Horizonte. 
Para os fins deste texto, apoiamo-nos em 20 entrevistas realizadas com integrantes de coletivos de Belo Horizonte. É a partir das falas de atores e atrizes sociais envolvidos em coletivos que atuaram nas Jornadas de Junho de 2013 que buscamos evidenciar a ambivalência dos conflitos em curso e o potencial destes em termos de socialização de sujeitos, de elaboração de quadros antecipados de reconhecimento e de construção de uma agência feminista de enfrentamento das desigualdades de gênero. Deve estar claro, portanto, que não entendemos as Jornadas de Junho e o conjunto de coletivos que a atravessam como necessariamente emancipatórios. Nosso argumento busca evidenciar como estes coletivos, que se entendem como emancipatórios e erguem bandeiras de justiça, são atravessados por muitas tensões, alimentando movimentos espasmódicos e ambivalentes acerca de questões de justiça.

\section{Conflitos sociais como processos complexos}

Lutas sociais são processos sempre ambivalentes. Elas não significam, automaticamente e a priori, o caminhar rumo a um telos emancipatório pensado de forma holística. Com isso, não se deseja questionar a relevância dos conflitos na geração de uma sociedade mais justa. Sem agonismo não há caminho plausível para um mundo menos opressivo. $\mathrm{O}$ que queremos argumentar, todavia, é que nem sempre os conflitos promovem um mundo mais justo, mesmo porque a justiça não pode ser entendida como um pacote fechado e bem amarrado. A ideia de um emaranhado de fios desencontrados e descontínuos parece mais adequada para se pensar a justiça. Deste emaranhado não há saída única e toda saída acaba, na prática, por deixar alguns fragmentos intocados, ou mesmo mais embolados do que antes. Lutas por justiça caminham, sempre de forma paralela, com a negligência a (ou a reprodução de) outras formas de injustiça.

Isso não implica, obviamente, que devamos simplesmente nos resignar à realidade existente. Nosso argumento não poderia caminhar nessa direção sob pena de tornar inútil qualquer 
discussão conceitual em torno da ideia de justiça. Menos resignado, nosso ponto é o da necessidade de reconhecer que conflitos sociais são processos complexos, repletos de idas e vindas, de progressos e retrocessos (Mendonça, 2014). São processos sinuosos em que não há solução final (muito embora haja soluções melhores do que outras). Soluções de justiça sempre portam ou provocam novas injustiças, sendo importante pensar esse processo, com o perdão do pleonasmo, em sua processualidade permanente. Neste sentido, a resignação é a reação oposta àquela que entendemos necessária diante das injustiças, justamente porque a luta é infindável.

Essa ambivalência que atravessa os conflitos sociais tem uma razão muito simples: tais conflitos são, como a própria expressão evidencia, sociais. Eles estão incrustados na teia de representações e interpretações que enquadram o mundo. Se esclarecem certos fragmentos desse mundo comum e os tematizam publicamente, eles também mantêm ou reforçam as sombras sobre muitos outros fios. É paradigmática, neste sentido, a forma como as lutas movidas por uma interpretação ortodoxa do marxismo ${ }^{5}$ levaram ao predomínio da ideia de classe e à negligência sistemática de categorias como raça e gênero. A necessidade de construir um sujeito coletivo de luta - o proletariado, no discurso predominante dos séculos XIX e da primeira metade do século XX - foi feita à custa de muitos fragmentos identitários que se viram sistematicamente invisibilizados, como bem demonstraram Laclau e Mouffe (1985).

5 É preciso enfatizar, aqui, que o adjetivo ortodoxo é fundamental para nosso argumento. Não estamos dizendo que houve uma completa negligência das questões raciais ou de gênero nos estudos marxistas, nem desconsideramos a importância de obras que investem na relação crítica entre marxismo e feminismo, tal qual A Mulher na Sociedade de Classes, escrita por Heleieth Saffioti ainda na década de 1960 (Saffioti, 2013). Tampouco desejamos advogar que as questões supostamente identitárias devam suplantar a relevância da classe nas lutas por justiça, mesmo porque não trabaIhamos com a dicotomia entre lutas materiais e lutas pós-materiais. Nosso argumento é o de que o marxismo ortodoxo, ao enfatizar as relações de classe, negligenciou a complexidade das lutas por justiça (agradecemos a Luís Felipe Miguel a crítica que levou à formulação mais clara desse aspecto). 
A literatura sobre confronto político e aquela sobre ação coletiva, de um modo mais geral, trazem alguns elementos que ajudam a compreender essa ambivalência inerente das lutas sociais. ${ }^{6}$ Isso porque elas evidenciam dois pontos: a) ações coletivas são construções situadas social e historicamente; e b) estas construções são dinâmicas e instáveis, sendo atravessadas por uma espécie de autorreflexividade que permite deslocamentos internos.

O primeiro desses pontos fica bastante claro em virtude do peso que os teóricos do confronto político colocam na ideia de oportunidade política. O confronto não se manifesta em um vácuo social. Ele não é uma mera expressão de um anseio coletivo formado abstratamente, mas algo que só pode ser compreendido dentro do contexto de sua emersão e expressão. McAdam, Tarrow e Tilly (2004) explicam que políticas de confronto são interações coletivas episódicas e públicas, não necessariamente violentas, em que uma das partes é o governo (como requerente, objeto ou parte das reivindicações). Dentro dessa perspectiva, Sidney Tarrow $(2009$, p . 27) é claro ao afirmar que o confronto político "surge como uma reação a mudanças nas oportunidades e restrições políticas em que os participantes reagem a uma variedade de incentivos", de diferentes tipos: "materiais e ideológicos, partidários ou baseados no grupo, de longa duração ou episódicos". O confronto emerge, assim, dentro de um contexto socio-histórico, com sua estrutura de oportunidades.

Tarrow (2009) e Meyer (2007) ressaltam, ainda, que aquilo que se configura como uma oportunidade, ou como uma restrição ao confronto político, altera-se ao longo do tempo e do espaço. É quando essas oportunidades são paulatinamente ampliadas que surgem os ciclos de confronto (Tarrow, 2009, p. 182). Profundamente imbricados no contexto em que se inserem, estes ciclos são necessariamente ambivalentes: eles são o fruto de um contexto social, ao mesmo tempo em que alargam os horizontes deste

6 Não é propósito deste artigo mapear, organizar e apresentar as distinções internas dessa ampla área de estudos. Sobre isso, já há vasta literatura, incluindo Tarrow (2009), Della Porta e Diani (2006) e Gohn (2014). 
contexto. Obviamente, tal alargamento não pode se dar, por mais radical que seja, em todas as direções simultaneamente, sob pena de tornar as lutas incompreensíveis e romper com a dinâmica interativa, que é o pressuposto de sua própria existência. Os confrontos assentam-se sobre estabilizações interpretativas que não são colocadas em xeque, reproduzindo muitas formas de opressão e criando outras.

Isso não significa, todavia, que os conflitos sejam estanques e preestabelecidos naquilo que portam de deslocamento e naquilo que induzem de reprodução das gramáticas vigentes, o que nos conduz ao segundo ponto supramencionado. Estes conflitos são instáveis e dinâmicos, transformando-se ao longo das próprias lutas. Confrontos políticos não são, repetimos, uma mera expressão de anseios já estabelecidos. O confronto tem um potencial transformador, fazendo com que as identidades sejam profundamente alteradas ao longo da luta (Laclau e Mouffe, 1985; Melucci, 1996; Tully, 2000; Markell, 2003). Como campo de ação, confrontos políticos promovem deslocamentos no contexto em que se inserem, afetando as próprias subjetividades, os interesses, as demandas e as reivindicações que alimentam essa luta.

Essa transformação dá-se tanto de maneira tácita quanto de forma mais autorreflexiva. A questão é que a agência implicada pelo confronto retroage sobre o contexto em que ela emerge e altera suas condições de possibilidade. Assim, os horizontes de justiça questionados/alimentados pelos confrontos não estão estabelecidos a priori,mas se deslocam ao longo da luta.

Aqui, a literatura sobre confronto político traz novos insights. É interessante notar, por exemplo, como Tarrow (2009) percebe que muitos movimentos sociais não são causa, mas consequência do ciclo de protestos em que se inserem, visto dependerem de uma densidade de conexão entre os sujeitos viabilizada pelo contexto de luta. Há de se destacar, ainda, entre os efeitos indiretos dos protestos, a socialização política das pessoas e dos grupos, a transformação de instituições e práticas políticas e as mudanças na cultura política (Meyer, 2003; Tarrow, 2009). Confrontos políticos 
têm consequências não previstas, cujos desdobramentos podem jogar luz sobre práticas desrespeitosas não tematizadas em um primeiro momento. Eles alteram a forma como os ativistas organizam-se, a maneira como se percebem e como dotam de sentido o contexto em que se inserem.

Nesse ponto, torna-se interessante convocar a segunda matriz teórica a alicerçar nosso argumento: a discussão de Axel Honneth sobre os paradoxos do contemporâneo e sobre a dimensão moral de lutas sociais. ${ }^{7}$ Ambos os pontos nos ajudarão a dotar de sentido a ambivalência emancipatória das Jornadas de Junho.

O primeiro ponto a ser destacado revela como processos tidos como emancipatórios são atravessados por novos dilemas e práticas opressivas. É o que deixa claro o filósofo alemão em sua discussão sobre alguns paradoxos contemporâneos. Honneth (2004) argumenta, por exemplo, que a crescente individualização gerada pelas sociedades ocidentais capitalistas teve um papel muito significativo na promoção da autorrealização (que o autor vê como a base da justiça). Ao mesmo tempo, contudo, ela fomentou novos processos de opressão, cujas marcas podem ser notadas em uma vasta gama de práticas sociais. Ela aparece, por exemplo, na demanda pela flexibilização das relações de trabalho, no crescente isolamento dos sujeitos e no generalizado sentimento de falta de propósito na vida. Paradoxalmente, a opressão acompanha o processo por meio do qual aumentaram os poderes de cada indivíduo de refletir e de desenvolver a autonomia.

The individualism of self-realization, gradually emergent over the course of the past fifty years, has since been transmuted having become an instrument of economic development, spreading standardization and making lives into fiction into an emotionally fossilized set of demands under whose

Neste artigo, não desejamos reconstruir tal abordagem ou defendê-la de seu crescente número de críticos. Tampouco aspiramos a assinalar suas semelhanças e diferenças em relação a pressupostos discutidos pelos teóricos do confronto político. 
consequences individuals today seem more likely to suffer than to prosper (Honneth, 2004, p. 474).

Em outro artigo, Honneth(em coautoria com Hartmann) expande essa discussão para tratar os paradoxos do capitalismo contemporâneo. De acordo com eles, o estabelecimento do capitalismo requereu a institucionalização do individualismo, de uma concepção igualitária de justiça legal, da vinculação do status a uma ideia de realização e do amor romântico (Hartmann e Honneth, 2006). Todos esses princípios promoveram, paradoxal e simultaneamente, avanços em termos de autorrealização e novas formas de opressão. De um lado, o aumento dos salários, do tempo livre e da autonomia; o fortalecimento de liberdades e direitos sociais; as conquistas feministas e de muitos movimentos sociais; a consolidação da ideia de relações puras - na acepção que Giddens (1993) dá ao termo. De outro, o individualismo, a responsabilização e a culpabilização dos sujeitos;a insegurança;as condições não razoáveis de trabalho;o produtivismo;o acirramento de desigualdades; a reificação do amor. Estes dois lados unem-se paradoxalmente em um todo complexo, no qual as condições para a emancipação tornaram-se responsáveis por minar sua própria possibilidade.

$\mathrm{O}$ segundo argumento honnethiano a nos interessar no escopo deste artigo é o que ressalta que o conflito social tem uma dimensão moral, justificando-se nãoapenas pelas conquistas diretas alcançadas, mas, sobretudo, pela capacidade de deslocamento de gramáticas morais e de antecipação de padrões futuros de reconhecimento (Honneth, 2003). ${ }^{8}$ Sem entrar nos detalhes do argumento honnethiano, o que queremos destacar aqui é que as próprias lutas exercem uma

8 Sem entrar nos meandros do debate dessa compreensão, conforme já pontuamos, vale lembrar que, em contraponto à noção honnethiana, a qual chama de paradigma identitário do reconhecimento, a autora feminista Nancy Fraser (2009) propõe o reconhecimento como condição intersubjetiva para a paridade de participação. Entendemos, assim, que Honneth e Fraser operam com visões muito distintas de reconhecimento. Como o ponto que nos interessa, neste texto, são os paradoxos da justiça, ativemo-nos às ideias de Honneth, que trata especificamente da questão. As ambivalências das lutas por justiça parecem-nos melhor abarcadas na compreensão honnethiana de reconhecimento. 
agência sobre os sujeitos que as promovem. Elas jogam luz sobre práticas desrespeitosas que não eram percebidas a priori e permitem ver outros mundos possíveis. Conflitos sociais podem permitir aos sujeitos oprimidos a visualização da injustiça contida nas práticas em que se inserem, bem como da possibilidade de práticas alternativas a estas. Ao colocar em xeque padrões enraizados de relações sociais, lutas abrem um espaço de contingência, permitindo que "fios" opressivos não notados em um primeiro momento ganhem atenção e que se vislumbre um mundo em que tais "fios" sejam neutralizados.

Os pontos trabalhados até agora já permitem compreender o tema central deste artigo. Interessa-nos perceber como a questão de gênero atravessa, de maneira paradoxal, o processo conflitivo das Jornadas de Junho de 2013. Por um lado, a questão não foi o estopim do ciclo de protestos, tendo passado, muitas vezes, despercebida em coletivos e manifestações. O fato de a questão não ser percebida $a$ priori possibilita que violências de gênero (enraizadas no cotidiano) manifestem-se na sua multiplicidade de formas e variedades. Em algumas circunstâncias, a própria tematização dessas questões pode ser entendida como inadequada, por enfraquecer e fragmentar lutas que deveriam unificar-se em torno de "questões mais amplas". Por outro lado, a movimentação gerada pelo ciclo de protestos também pode estimular a tematização de múltiplas formas de desrespeito não percebidas a princípio, incluindo as de gênero. $O$ conflito social em andamento acaba por instigar a tematização de outras formas de opressão que perpassam este mesmo conflito, expandindo seus horizontes de atuação.

Surge, assim, uma fissura na dominação (Biroli, 2013). Esta fissura possibilita a antecipação de quadros de reconhecimento e o fortalecimento da autonomia. Com isso, damos o terceiro e último passo teórico para prosseguir com nossa análise: a discussão feminista sobre autonomia. Uma vez mais, ressaltamos que há muitas tensões entre diversas feministas (em sua multiplicidade) e o pensamento tanto de Honneth quanto dos autores e das autoras da abordagem do confronto político. A articulação 
que sugerimos parte dos pontos específicos expostos anteriormente para pensar fissuras da dominação e possibilidades de fortalecimento da autonomia.

Parece natural pensar a agência autônoma no interior de ciclos de confronto político, em que gramáticas sociais estão sendo, ambivalentemente, construídas e reconstruídas. Ir às ruas, expressar questionamentos, debater ou reafirmar opiniões foram comportamentos identificados em homens e mulheres que participaram das Jornadas de Junho. Ser autônomo e ter liberdade de escolher participar pareciam igualar aqueles sujeitos tão diversos. Uma análise mais detida da construção política e da vivência da autonomia pelas mulheres revela, contudo, que esses leques de escolhas, apresentados como iguais, estruturam-se sob bases bastante diferentes.

A autonomia é um dos valores mais caros ao pensamento democrático. Em rápidas palavras, a capacidade de viver a partir de suas próprias escolhas, buscando a autossatisfação sem interferir na vida de outrem é marcante no pensamento político, desde John Stuart Mill aos autores do liberalismo igualitário, influenciando a própria construção dos regimes democráticos. O feminismo desafiou os limites de tal proposição, ao dar corpo ao abstrato sujeito autônomo do liberalismo (Biroli, 2013). As autoras feministas mostraram que a existência de facilitadores formais e a inexistência de normas coercitivas para o exercício da autonomia não a tornam igualitária para homens e mulheres, já que os horizontes de possibilidade são anteriormente construídos de forma desigual (op. cit.). Para isso, buscarão identificar as barreiras para a vida autônoma e os elementos que inscrevem a subordinação. ${ }^{9}$

9 O debate sobre autonomia é conflitante dentro da própria teoria feminista (Biroli, 2013). De um lado, há feministas que defendem o ideal neutro de autonomia, muito próximo à concepção liberal. Pensam a autonomia a partir da justiça do procedimento para alcançá-la, justaposta à autoexpressão dos valores desejados, a partir da ausência de coerção. De outro lado, é conhecida como maternalista, contesta o próprio valor da autonomia, justificando-se a partir do fato de que as mulheres dispensam cuidado a outrem durante toda sua vida e essa experiência não pode ser desconsiderada. 
Na trilha de Biroli (2013, p. 35), entendemos que é necessário pensar criticamente sobre a ideia de autonomia, porque mulheres a vivenciaram de forma limitada, na medida em que hierarquias de gênero restringem suas possibilidades de escolha. Para a autora, "a agência é sempre imperfeita em relação ao ideal normativo da autodireção e autodeterminação pelos indivíduos de suas preferências" (Biroli, 2012, p. 27). Ao olhar para a experiência das mulheres, Biroli (2012;2013) enfatiza que essa imperfeição torna-se "regular" e não apenas um "desvio". Isso sinaliza para um contexto sistêmico e prévio de opressão, mesmo que não formal.

É a partir de tais premissas que Biroli (2013) debate com Young e McKinnon a necessidade de recolocar a dimensão corpórea na luta por autonomia, não no sentido estritamente biológico, mas pensando o corpo como um produto das permissões sociais e das relações intersubjetivas dos indivíduos. O conceito de corpo vivido de Young (1980) combina a ideia de um corpo físico com a de experiência contextualizada. Para a autora, é o que permite entender que uma mulher negra, lésbica e pobre, por exemplo, não é apenas uma sobreposição de identidades de grupos marginalizados, mas tem uma especificidade, uma individualidade. E mais, a forma como cada uma destas identidades é vivida torna-se distinta entre as mulheres, mas ajuda a entender a estrutura desigual em que as possibilidades de escolhas são construídas e a autonomia é vivenciada.

A autora bell hooks também atribui à experiência corporificada dos grupos marginalizados uma das formas especiais, ainda que não a única, de construção de conhecimento sobre mundo e suas desigualdades, pensando especialmente o caso das mulheres negras. Para ela, a vivência da opressão subsidia "um modo de conhecer que muitas vezes se expressa por meio do corpo, o que ele conhece, o que foi profundamente inscrito nele pela experiência" (hooks, 2013, p.122).

A questão que se coloca, então, é: como diferenciar as experiências autônomas de fato daquelas que foram historicamente construídas para as mulheres como tipicamente femininas (tornando 
pouco evidentes outras possibilidades de vida)? Para McKinnon (1989 apud Biroli, 2013), a possibilidade de fazer escolhas autônomas estaria na tomada de consciência da dominação e no compartilhamento de experiências vividas, que embasam um conhecimento vivido. De acordo com ela, toda a construção do Estado e da cultura deu-se sob uma ótica masculina, e, por conta disso, as mulheres possuem uma visão mistificada de si. A autora não retira das mulheres a capacidade de fazer seus próprios julgamentos; pelo contrário, aposta na possibilidade de que elas mudem esse padrão, ao descortinarem as estruturas de opressão em duas dimensões: "na descoberta do que é comum às mulheres e daquilo que lhes foi privado na condição de mulheres" (Biroli, 2013, p. 81).

A socialização feminina, e, nesse caso, feminista, ocorre quando as mulheres se dão conta da subjugação, quando descobrem imposições históricas sob as quais construíram suas identidades, escolhas ou preferências. É esse momento de "fissura na dominação" (Biroli, 2013, p. 82) que promove a construção de uma agência mais autônoma. Pensar a autonomia feminina como regularmente dotada de privações e a possibilidade de reverter esse quadro a partir do compartilhamento de experiências é relevante para entender o engajamento feminino nos episódios de confronto político e em seus desdobramentos. Ao se tornarem conscientes de um processo opressor interno a um grupo em confronto, as mulheres passam a experimentar um tipo de socialização que impacta suas vidas como militantes políticas e como mulheres.

$\mathrm{O}$ estudo de caso explorado neste artigo busca mostrar como os conflitos sociais expressos nas Jornadas de Junho são atravessados por várias formas de opressão de gênero, mas, paradoxalmente, a própria luta joga luz sobre essas mesmas violências, criando condições de possibilidade (oportunidades políticas; fissuras na dominação) para a antecipação de padrões de reconhecimento e o fortalecimento da autonomia. Não vemos, portanto, estes conflitos como meramente emancipatórios ou como geradores de opressões. 
Essa luta, que se transforma ao longo de seu processo, é ambivalentemente emancipatória, oscilando entre a reprodução do desrespeito e a tentativa de seu deslocamento. ${ }^{10}$

\section{Gênero e manifestações}

Pensar o lugar das relações de gênero no contexto de manifestações públicas que ventilam pautas emancipatórias só é possível a partir do entendimento, já anunciado, da oscilação entre comportamentos desestabilizadores de desigualdades e a ratificação de padrões que as legitimam. Moghadam (2013; 2014) e Johansson-Nogués (2013), ao pesquisarem sobre os papéis desempenhados pelas mulheres na Primavera Árabe e os resultados daquelas lutas públicas para a vida feminina, sustentam que esses momentos podem acirrar desigualdades. Basta lembrar a forma como, na Líbia, as forças de Gaddafi usaram do estupro de mulheres para humilhar os inimigos, tratando-as como extensão masculina e moeda de troca nos conflitos. Ou, ainda, como a violência sexual foi arma para dissuadir a participação feminina no Egito (Johansson-Nogués, 2013). ${ }^{11}$

Moghadam (2014) enfatiza que o status de direitos conquistados anteriormente diz muito sobre os impactos posteriores e o próprio tratamento recebido pelas mulheres nos espaços de ocorrência e disputa dos protestos. A pouca participação política das egípcias e a violência sofrida na Praça Tahir(Cairo, Egito) são elementos importantes para a compreensão da dificuldade de transição democrática daquele país e do que "sobrou" para as mulheres após aquela Primavera.

10 É preciso enfatizar que a relação (e análise), na maioria das vezes tensa, do feminismo no interior dos movimentos de esquerda no Brasil não é nova, assim como existe um acúmulo de discussões entre feminismo e marxismo, em que se destaca o famoso artigo de Hartmann (1996). A tensão é documentada na literatura nacional especialmente no período da ditadura, quando ficou famosa a dicotomia "luta geral" (contra o regime) versus "luta específica" (contra a desigualdade de gênero) (Pedro, 2006; Pedro e Wolf, 2010; Sarti, 2004).

11 Vale lembrar, aqui, a interessante discussão sobre mulheres na guerra construída por Jean Elshtain (1987). 
By way of our gendered approach to the Arab Spring, we have uncovered how the outcome of the "democratic revolutions" may be less democratic than we would normally like to believe. In the midst of social reordering, there are no guarantees that pre-existing rights (however limited) of the country's different social collectives will be honoured and maintained. Similarly, in the aftermath of democratic elections, there are no guarantees that the new government will seek to address the legitimate concerns of its citizens (Johansson-Nogués, 2013, p. 405).

No caso das Jornadas de Junho brasileiras, questões de gênero passaram frequentemente despercebidas tanto pela mídia quanto por diversos pesquisadores que discutem o processo (Nogueira, 2013; Ricci e Arley, 2014; Maricato et al., 2013; Castells, 2013; Nobre, 2013; Mendonça e Ercan, 2015;Malini et al., 2016; Ortellado, 2013). Este artigo busca dar um primeiro passo nessa direção, evidenciando que, se não há relatos de estupros coletivos frequentes nas manifestações brasileiras (como na Líbia e no Egito), isso não significa a inexistência de práticas violentas contra mulheres no âmbito desses protestos.

Antes de explicar a estratégia metodológica empregada para realizar tal discussão, cabe, aqui, uma breve contextualização dos protestos que tomaram as ruas de diversas cidades brasileiras em junho de 2013. Geralmente, o evento mobilizado para delimitar o início desse processo é o ato do dia 6 de junho, puxado pelo Movimento Passe Livre (MPL) em São Paulo, contra um aumento das tarifas de transporte público (Judensnaider et al., 2013). ${ }^{12} \mathrm{O}$ evento está inserido em um contexto de protestos multitudinários em diversos países (Castells, 2013) e é alçado a uma condição de grande visibilidade pela aproximação da Copa das Confederações. Manifestações massivas logo se alastraram pelo país, levando milhões de pessoas às ruas (Ricci e Arley, 2014; Nogueira, 2013).

12 Com isso, não desejamos nos inserir na polêmica sobre o "início efetivo" desse processo, mesmo porque acreditamos que diversas narrativas sobre ele são possíveis, estabelecendo linhas de associações distintas. 
Com uma grande diversidade de pautas, muitas delas conflitantes, manifestantes (em coletivos ou individualmente) clamavam pelo direito à cidade, contra a corrupção, contra os elementos do sistema político (representantes, partidos e regras) e pela melhoria de serviços públicos variados (Ricci e Arley, 2014; Nogueira, 2013). Em termos quantitativos, tais atos têm seu ápice na segunda metade do mês de junho, mas deixam um legado -difuso e ambivalente - de organização de protestos, discussões e práticas mobilizatórias.

É importante salientar que esse processo político não foi uma emergência inusitada sem conexão com fatores que lhe antecedem. Neste sentido, e de forma um pouco arbitrária, deve-se citar, pelo menos, o histórico de lutas sociais em torno da questão do transporte público, que remonta à Revolta do Buzu em Salvador (2003) e à Revolta da Catraca em Florianópolis (2004-2005), passando pela fundação do MPL (2005) e por atos públicos em diversas capitais do país no primeiro decênio do século XXI (Pomar, 2013; MPL, 2013). Merece menção, também, a estruturação de movimentos de atingidos por megaeventos, tais como as mobilizações em torno dos Jogos Pan-Americanos (2005) e a Articulação Nacional dos Comitês Populares da Copa (Ancop) (2010) (Vainer, 2013; Ricci e Arley, 2014). Tratam-se de agendas inseridas em uma discussão mais ampla sobre o direito à cidade, que impulsiona ocupações de espaços públicos em diversas localidades do Brasil, incluindo o caso de Belo Horizonte (Ricci e Arley, 2014).

Em um plano mais geral, convém salientar o esgotamento do modelo de desenvolvimento calcado no consumo promovido pelo Lulismo, a ascensão de uma nova classe média com suas reivindicações (Ricci e Arley, 2014; Nogueira, 2013) e as dificuldades de articulação política da então presidente Dilma Rousseff em seu primeiro mandato, que contribuem para a reativação de parte da sociedade civil que apoiou o governo do Partido dos Trabalhadores (PT) por um longo período (Nogueira, 2013).

No plano internacional, como já mencionado, é inegável que a onda de protestos em diversos países (incluindo Egito, Estados Unidos, Espanha e Turquia) deixa marcas sobre a mobilização 
nacional, ao evidenciar a possibilidade de uma ocupação multitudinária de espaços públicos e o potencial de redes sociais na capilarização de um sentimento de indignação contra a política institucional em diversos contextos (Lim, 2012; Castells, 2013, Jensen e Bang, 2013; Penney e Dadas, 2014; Wojcieszak e Smith, 2014; Mendonça e Ercan, 2015).

No que se refere às consequências das Jornadas de Junho, é importante compreender que elas não terminam em junho, mas continuam reverberando nos processos políticos que o sucedem. Elas se manifestaram de forma mais imediata em uma pressão exercida sobre o poder público, expresso não apenas na queda do preço das tarifas em 2013, mas na votação de uma série de medidas, como a rejeição da Proposta de Emenda à Constituição (PEC) 37, a destinação de $75 \%$ dos royalties da exploração de petróleo para a educação e a definição da corrupção como um crime hediondo. As consequências de tais Jornadas, todavia, vão além dessas mudanças mais visíveis e envolvem a geração de debates públicos, a rearticulação de coletivos políticos, a maior visibilidade pública de grupos conservadores, o declínio na popularidade de diversos políticos e partidos, sobretudo de Dilma Rousseff e do PT (Feres Júnior, Miguel e Barbarela, 2014) e a articulação dos protestos massivos de 2015.

Neste artigo, interessa-nos pensar especificamente sobre a forma como questões de gênero atravessam esse processo e suas consequências. Essa análise foi suscitada pela emergência da temática em um conjunto de entrevistas semiestruturadas realizadas com 59 manifestantes de Belo Horizonte e de São Paulo. Tais entrevistas foram realizadas com o emprego da estratégia de bola de neve, em que os/as próprios/as entrevistados/as indicam as próximas pessoas a serem ouvidas. Inicialmente, traçamos um mapa de coletivos e grupos envolvidos com as manifestações a partir da leitura de publicações sobre o tema e de conversas exploratórias com ativistas. Iniciamos o processo das entrevistas com a procura dos coletivos, a partir dos quais derivamos os/as entrevistados/as subsequentes. Asseguramos, ainda, a realização de algumas entrevistas com 
pessoas não mobilizadas em coletivos. No entanto, reconhecemos, de saída, que o corpus empírico é atravessado por importantes vieses, não se propondo a ser representativo das Jornadas de Junho em sua integridade.

Neste estudo, trabalhamos com 20 entrevistas realizadas em Belo Horizonte, embora façamos breves menções a questões que emergiram em entrevistas no município de São Paulo. Nas 20 entrevistas, foram mencionados vínculos aos seguintes coletivos, associações ou partidos: Tarifa Zero, Assembleia Popular Horizontal (APH), Comitê Popular dos Atingidos pela Copa, Brigadas Populares, Embaixadores de Minas, Turma do Chapéu, Coletivo da Educação do Campo, União Nacional dos Estudantes, Movimento de Luta nos Bairros Vilas e Favelas (MLB), Fica Ficus, TZ, Viaduto Ocupado, Conjunto Vazio, Espaço Estilingue, Família de Rua, Fora Lacerda, Ocupação Luiz Estrela, Levante Popular da Juventude e Partido Socialismo e Liberdade (PSOL). Além disso, seis pessoas entrevistadas declararam-se "independentes" ou sem vínculo a associações.

Nas transcrições, buscamos mapear, em primeiro lugar, os diversos relatos de práticas opressivas e violências relacionadas a gênero. Na sequência, mapeamos trechos que apontavam tentativas de tematizar e questionar tais práticas. À luz das discussões sobre confronto político, reconhecimento e autonomia, identificamos como a experiência das mulheres demonstra o enraizamento da dominação masculina e também encerra suas possibilidades de fissura.

\section{Novos contextos de luta, dilemas antigos}

A análise a seguir concentra-se em dois processos que se tornaram perceptíveis nas narrativas dos/as entrevistados/as. O primeiro deles diz respeito à identificação da desigualdade de gênero no contexto dos protestos. O segundo é a forma de enfrentamento ao desrespeito com viés de gênero desencadeado no interior das arenas constituídas durante e no pós-junho e as "lições" pedagógicas desse processo. Esses processos apresentam-se, neste texto, por meio de relatos pessoais de vivências expressas nas entrevistas. 
Essa personalização dos acontecimentos nas falas é parte da forma como estruturas, práticas e questionamentos da dominação manifestam-se e atualizam-se encarnados nas experiências de sujeitos corporificados. É por meio da verbalização de muitos "eus" ou percepções de "nós" que se joga luz sobre a desigualdade de gênero como histórica e sistêmica. Isso não significa, contudo, que defendamos uma redução da estrutura patriarcal da sociedade às suas manifestações singulares.

\section{a) O desrespeito}

Gritos machistas durante as manifestações, violência policial marcada pela misoginia, sobreposição de falas ou pouca participação de mulheres nas assembleias e violência sexual nas ocupações destacaram-se nas falas dos/as entrevistados/as quando questionados/as sobre como percebiam relações de gênero nas (e a partir das) Jornadas de Junho. Obviamente, essas diversas experiências têm pesos distintos e revelam formas diversas de opressão, mas todas elas, de algum modo, ilustram a presença do desrespeito de gênero no processo das Jornadas de Junho de 2013.

Nota-se, em primeiro lugar, a emergência da opressão de gênero na própria performance de atos públicos, havendo relatos da reprodução de comportamentos desrespeitosos que atravessam o cotidiano. "Essas coisas que a gente já está quase que acostumada, mas não acostumamos jamais, né? Que é gritos violentos, cantadas, menino passando a mão, forçando alguma coisa ou outra" (informação verbal), ${ }^{13,14}$ lembra uma ativista. Tal percepção também aparece em falas masculinas, que notam que, por vezes, o "espaço da manifestação virava uma micareta, de afirmação dessa coisa masculina", além da sobreposição das falas das mulheres "meio subentendida ou de maneira mais explícita" (informação verbal). ${ }^{15}$ Os relatos

\footnotetext{
13 As entrevistas foram realizadas por um conjunto de pesquisadores que participam do projeto (Márcia Cruz, Rayza Sarmento, Stephanie Reis, Selene Machado, Davi Figueiredo, Márcio Bustamente e Ricardo Fabrino Mendonça), os quais geralmente atuavam em duplas. Optamos por não mencionar os nomes dos entrevistadores em cada entrevista, nem o local exato delas.

14 Entrevista concedida pela ENTREVISTADA B. Entrevista. [16 dez. 2014]. [S.I.], 2014.

15 Entrevista concedida pelo ENTREVISTADO C. Entrevista. [17 out. 2014].[S.I.], 2014.
} 
sugerem o caráter difuso do confronto político quando espraiado para além de um grupo ou de uma reivindicação específica. A ida às ruas naquele momento, para muitos, não pressupunha colocar em xeque hierarquias de gênero.

A abordagem policial também evidenciou o tratamento desigual a homens e mulheres. Os relatos trazem a forma como a revista feminina era conduzida por policiais homens, a ocorrência de xingamentos como "puta" e "vagabunda", além da percepção de que as mulheres eram alvos mais recorrentes dos policiais. Sobre a relação dos policiais com os manifestantes, em uma das entrevistas é lembrado como a suposta fragilidade feminina foi utilizada na contenção das ações: "existe uma tentativa de atingir as pessoas mais fracas [...]; não que a mulher seja mais fraca, eu não estou dizendo isso, mas ela fica muito mais fragilizada por conta da nossa cultura que ensina o homem a ser violento" (informação verbal). ${ }^{16}$ Longe de nos filiarmos a uma perspectiva biologizante, isso é sintomático para entender como a experiência corporificada do ser mulher é fonte de um tipo de opressão bastante específica, como pontuam bell hooks (2013) e Iris Young (1980).

Se expressões de machismo fizeram-se presentes no percurso das ruas, elas também se tornaram evidentes nos espaços estruturados para a discussão da conjuntura política e das táticas de atuação e preparação de novos atos. Isso pode ser notado, por exemplo, nas APHs que ocorriam em Belo Horizonte, sob o Viaduto Santa Tereza, local de resistência cultural localizado no centro da cidade. Essas assembleias eram palco de discussões sobre as estratégias de atuação dos ativistas e as reivindicações que deveriam fazer. Adotando um discurso de ênfase na horizontalidade e de supressão de hierarquias, as assembleias foram cenário de algumas práticas desrespeitosas.

Entrevistados e entrevistadas relatam tensões advindas da predominância de falas masculinas, do corte de falas femininas e da composição da comissão que definia a metodologia da assembleia.

16 Entrevista concedida pelo ENTREVISTADO C. Entrevista. [17 out. 2014]. [S.I.], 2014. 
De acordo com um dos ativistas, com a ponderação gradativa dessas desigualdades, ficou "evidenciado um machismo que existe nos meios [...] ditos libertários" (informação verbal). ${ }^{17}$ As mulheres chegaram a criar um símbolo - "o corta pinto"18 - para sinalizar manifestações misóginas. Entendemos que essa restrição do acesso à fala livre pode ser lida como um dos elementos que constituem a regularidade da agência imperfeita definida por Biroli (2013). O discurso das APHs é de que todos ali estavam em "pé de igualdade". Entretanto, a expressão das mulheres, constantemente cerceada de formas direta ou implícita, demonstra que essa condição não é respeitada.

As lembranças mais frequentes de entrevistados/as sobre a relação entre gênero e manifestações referem-se a ocorrências relativas à ocupação da Câmara de Vereadores de Belo Horizonte, realizada entre 29 de junho a 7 de julho de 2013, em protesto contra o aumento da tarifa de ônibus na capital. Os/as participantes debateram se a construção do grupo negociador deveria ser paritária ou composta pelas "pessoas mais capazes, independentemente do gênero" (informação verbal). ${ }^{19} \mathrm{~A}$ reflexão de um dos ocupantes é bastante ilustrativa de como essa negação aponta, novamente, para a compreensão das dificuldades de expressão feminina: “a maioria fala: 'não, não é o momento de falar sobre isso' [...]. Nós, homens, o espaço público foi feito pra (sic)gente. A gente aprende a falar e é obrigado a falar... mas isso (da paridade) vai ficando mais evidente" (informação verbal). ${ }^{20}$

Diz muito sobre as diferentes nuances da dominação masculina perceber como os espaços da sociedade civil também padecem dos mesmos problemas do sistema político formal. A dificuldade de acesso das mulheres a cargos eletivos (Phillips, 1995), ou, mesmo quando eleitas, a ênfase midiática em sua aparência e menos em sua atuação (Miguel e Biroli, 2011; Ross e Byerly, 2006; Sarmento, 2013;

17 Entrevista concedida pelo ENTREVISTADO E. Entrevista. [8 out. 2014]. [S.I.], 2014.

18 O gesto expressa-se por um braço erguido, cuja base é interceptada, perpendicularmente, pelo outro braço, com a mão aberta e os dedos unidos.

19 Entrevista concedida pelo ENTREVISTADO C. Entrevista. [17 out. 2014]. [S.I.], 2014.

20 Entrevista concedida pelo ENTREVISTADO F. Entrevista. [10 dez. 2014].[S.I.], 2014. 
Sreberny e Van Zoonen, 2000) e o tratamento diferenciado que recebem ao ocuparem espaços públicos não são muito distintos dos fatos relatados aqui.

Casos de violência sexual contra as mulheres também aparecem nos relatos sobre a ocupação da Câmara,um deles com denúncia formal à polícia. Dois homens foram nominalmente acusados em uma nota pública, assinada por parte dos/as manifestantes da ocupação. O texto afirma que a Frente de Mulheres constituída em tal arena teve sua fala desconsiderada quando tentou discutir o problema.
A reunião mostrou que mesmo ambientes políticos e com pretensões emancipatórias não estão livres de reproduzir o padrão normativo do opressor [...]. A primeira reação da maior parte dos ocupantes foi defender o direito de resposta dos agressores e principalmente colocando em xeque a confiabilidade das agredidas (Assembleia Popular Horizontal Belo Horizonte, 2013).

A referida nota identifica os dois homens e frisa a expulsão de ambos da ocupação.

Outro caso de violência sexual, amplamente discutido em diversas entrevistas, está relacionado a duas pessoas de partidos diferentes, o que criou tensões ainda mais fortes, dado que a denunciante foi posta em dúvida, como conta uma das mulheres:"aí gerou a polêmica toda que a gente está acostumada, que 'ah, ela tá inventando porque ela quer prejudicar o partido"' (informação verbal). ${ }^{21} \mathrm{O}$ acusado, militante conhecido na capital e entrevistado pela pesquisa, afirma discordar de que tenha havido estupro. Ele também contesta a forma como o assunto foi enfrentado no interior da ocupação. Para ele, "a menina era de um partido político; esse partido político articulou essa nota no sentido de desgastar" (informação verbal), ${ }^{22}$ dada sua influência na militância e sua

21 Entrevista concedida pela ENTREVISTADA H. Entrevista. [18 nov. 2014]. [S.I.], 2014.

22 Não será colocada nenhuma identificação nessa entrevista para não identificar suas demais falas. 
origem social ("pobre, negro e morador da periferia”). Houve uma grande articulação das mulheres para mostrar que se tratava de um caso de violência de gênero e que precisaria ser combatido como tal.

Essa dificuldade de problematizar as questões que afetam as mulheres no interior de movimentos hierárquicos ou autogestionados é percebida recorrentemente pelas ativistas: “a acusação que a gente mais ouve é que os movimentos feministas estão tentando desarticular os movimentos" (informação verbal). ${ }^{23}$ Nas idas e vindas da luta por justiça, elementos que compõem um complexo quadro de opressão estrutural atravessam-se e, muitas vezes, alimentam tensões concernentes às prioridades dos movimentos.

Cabe mencionar, ainda, que, dentro dos coletivos, tensões e práticas de desrespeito manifestam-se sistematicamente. Uma entrevistada explica que tais grupos, por mais que lutem por causas emancipatórias, reproduzem as opressões enraizadas no cotidiano da sociedade que desejam alterar.

Como a gente vive numa sociedade machista, é hipócrita dizer que as organizações de esquerda não têm machismo. Têm. [...] Ali se reproduziu muito do que a gente não quer que seja reproduzido na nossa sociedade, o que é natural, né? Não somos pessoas que vivem completamente fora da sociedade; “somos puros”. Não tem jeito. Impossível (informação verbal). ${ }^{24}$

A contar sobre a formação da Frente Feminista da sua organização, que é anterior às Jornadas, uma entrevistada relembra a resistência de alguns membros em usar o termo. Ela afirma que os discursos mobilizavam "aquela famosa máscara que a gente está acostumada a conviver: 'ah, se é feminista, tem que por também que é também antirracista, anti-homofóbica, anti não sei o quê"” (informação verbal). ${ }^{25}$

23 Entrevista concedida pela ENTREVISTADA H. Entrevista. [18 nov. 2014]. [S.I.], 2014.

24 Entrevista concedida pela ENTREVISTADA O. Entrevista. [10 mar. 2015]. [S.I.], 2015.

25 Op. cit. 
Por vezes, os coletivos reproduzem a própria dicotomia entre esferas pública e privada, a partir da divisão de tarefas entre integrantes. Uma das entrevistadas relata: "quando tem atividade de cuidar das crianças, limpeza, cozinha, $80 \%$ são mulheres e $20 \%$ são homens e eles estão sempre nas discussões teóricas" (informação verbal). ${ }^{26} \mathrm{Ou}$ seja, há uma dificuldade em participar das discussões do grupo, dada a não divisão paritária dos afazeres domésticos.

As falas reportadas nesta seção ilustram o argumento de que as lutas por justiça não se dão linearmente e de forma monolítica. Como frutos do contexto em que se inserem, elas atualizam muitos dos valores e das práticas comportamentais tácitos que alimentam diversas injustiças, incluindo as de gênero. Seja na violência do policial, seja no abuso sobre o corpo de mulheres em uma ocupação, seja no cerceamento da fala delas em assembleias, com as devidas diferenças entre tais práticas, tem-se a atualização de uma sociedade patriarcal que atrela os privilégios da existência pública a homens, mantendo o ônus desta existência sobre as mulheres. A luta impulsionada por tais atores, ainda que alicerçada em ideais emancipatórios, é atravessada por paradoxos, como já antevia Honneth (2004).

Também paradoxalmente, contudo, entendemos que a emergência do desrespeito em um contexto como o das manifestações, marcado por uma ruptura na ordinariedade da experiência que aguça a sensibilidade a questões usualmente invisíveis e abre possibilidades de reflexividade, tem potencial emancipatório. Sem atenuar o peso dessas formas de desrespeito, apontamos seu potencial desvelador na tematização da opressão. Perceber-se como silenciada ou ainda como privilegiado no uso da fala, por exemplo, remete-nos à forma como a autonomia é vivenciada de maneira distinta e como o confronto político tem um papel importante em clarificar essas distinções. Processos agonísticos evidenciam a opressão e permitem seu questionamento nas relações com outros atores sociais. Assim, movemo-nos à próxima seção, que trata 
do questionamento do desrespeito ao longo do processo político derivado das Jornadas de Junho.

b) $\mathrm{O}$ enfrentamento ao desrespeito e o aprendizado

Se a emergência do conflito social realça práticas opressivas nem sempre percebidas, como propõe Honneth $(2003 ; 2004)$, a construção compartilhada de conhecimento e experiência, junto do entendimento de uma autonomia cerceada, foi fundamental no caso das mulheres entrevistadas em Belo Horizonte, para que as situações de machismo fossem questionadas. As narrativas de algumas entrevistadas revelam o aprendizado pessoal das mulheres em reconhecer-se como silenciadas e também como feministas.

Um dos processos de enfrentamento mais contundentes foi a formação de uma Frente Feminista em um coletivo que surgiu no contexto das manifestações, buscando o que Scherer-Warren (2014, p. 56) chama de "democratização de práticas cotidianas internas aos grupos". O movimento Tarifa Zero é um desdobramento do Grupo de Trabalho de Mobilidade Urbana das APHs e luta pelo passe livre universal. Sua Frente Feminista surge a partir da constatação das mulheres do movimento de que, mesmo em um espaço que busca subverter alguns padrões políticos e sociais, a desigualdade de gênero e o machismo ainda se faziam presentes. A desigualdade tornou-se mais clara com a visibilidade do movimento na mídia durante o reajuste tarifário:"durante esse período em que o Tarifa Zero estava fazendo muita pressão pra (sic)essa questão do reajuste tarifário, algumas figuras (homens) tavam (sic) tendo mais destaque, digamos assim, né, tavam (sic) sendo mais procuradas pra (sic) falar na mídia" (informação verbal). ${ }^{27} \mathrm{~A}$ discussão interna ao movimento começou por defender a paridade entre integrantes para conceder as entrevistas e avançou até a definição, por parte das mulheres, de que somente elas seriam fontes dos jornais, o que teria trazido novos aprendizados. Tal experiência remete à histórica problematização do espaço público pelas mulheres,

27 Entrevista concedida pela ENTREVISTADA N. Entrevista. [17 nov. 2014].[S.I.], 2014. 
no ativismo e na teoria política. Confrontando uma primeira ideia habermasiana masculinizada de esfera pública, depois corrigida pelo autor, Young (2000) mostra como as regras da prática discursiva funcionam como motores de exclusão do espaço público. Segundo a autora, uma das formas de remediar tal problema de silenciamento é feita por meio das narrativas pessoais,que, longe de serem apolíticas, colaboram para uma troca reflexiva que ajuda na construção de remédios para as injustiças. É o que evidencia o trecho a seguir: a necessidade, percebida em grupo, de aprender mais sobre a substância da questão defendida (tarifa de ônibus) para assumir um lugar público.

Eu lembro que no início muitas meninas ficaram resistentes, falaram "deixa ser paridade mesmo; não precisa ser tão feminista sabe?" [...]. A gente foi criando estratégias entre nós que alcançou uma coerência enquanto grupo de mulheres. [...] A gente viu que realmente tinha um deficit ali, "pô tenho que correr atrás dessas informações, daqui a pouco a repórter vai me ligar e aí eu não sei dizer se o reajuste de 20 centavos é justo ou não e por quê" [...], a gente não tem facilidade, muitas meninas nunca tinham falado em público (informação verbal). ${ }^{28}$

Outra iniciativa foi uma apresentação sobre machismo feita pela Frente Feminista do Tarifa Zero durante um seminário interno de definição de diretrizes da organização. As mulheres sistematizaram dados com percentual de falas e comparecimento nas reuniões, expondo aos homens situações naturalizadas de desrespeito. Ainda que o percentual de mulheres presente fosse muito semelhante ao de homens, havia assimetrias abissais no tempo e número de falas, bem como reiterados cortes das falas das mulheres. 
A gente resolveu fazer várias estatísticas assim, do marco do machismo no TZ [Tarifa Zero]. Pegamos a presença em reunião, o percentual de homens e mulheres, o percentual de falas e pegamos também grandes gafes masculinas, assim, algumas frases. Então a gente fez uma apresentação [...]do percentual de falas em reunião, aí já deu $75 \%$ pra (sic) homem e $25 \%$ pra (sic)mulher [...]. A gente fez uma coletânea de frases muito marcantes que tiveram, sem citar nomes, ou seja, qualquer pessoa poderia ter falado. Aí, colocamos frases tipo assim "ah, eu acho que a mulher que tem fazer ata, porque mulher é mais organizada" (informação verbal). ${ }^{29}$

Pensar a autonomia feminina como regularmente dotada de privações e a possibilidade de reverter esse quadro a partir do compartilhamento de experiências é relevante para entender o engajamento feminino nos episódios de confronto político e em seus desdobramentos. O feminismo torna-se uma "prática" na vida de uma das entrevistadas durante essa caminhada de militância pela mobilidade urbana. Ela descreve a inexistência de uma formação prévia: "não teve um momento de reflexão, de leitura, de nada, ao mesmo tempo em que a gente tava ( $\mathrm{sic}$ ) aprendendo a gente tinha que lidar com a situação" (informação verbal). ${ }^{30}$

A socialização política oriunda e/ou fomentada por esse processo é um ganho indireto de extrema importância para a vida das pessoas e dos grupos, mas também das sociedades, como destacam Meyer (2007) e Tarrow (2009). No caso específico das mulheres, isso é potencializado, dado que precisam combater uma estrutura social e histórica de opressão, inclusive para serem ouvidas dentro de movimentos emancipatórios. O desrespeito alimenta um tipo de reflexividade que permite a sujeitos repensarem-se e redefinirem-se. Ao fazê-lo, projetam outros horizontes possíveis e antecipam padrões mais justos de sociedade (Honneth, 2003). As mulheres da Frente Feminista mobilizaram acontecimentos 
que as privavam da vivência de uma igualdade plena com os demais membros do coletivo, a fim de questioná-las. Esse conhecimento vivido das mulheres surge do "reconhecimento que sua experiência não é individual, mas compartilhada. Seu mal-estar não resulta de algum tipo de desajuste individual [...].Nessa perspectiva, a agência autônoma é possível quando a dominação é superada" (Biroli, 2013, p. 52).

Relatos masculinos também indicam um aprendizado gradativo ao observarem as intervenções públicas realizadas pelas mulheres nas situações em que se sentiam desfavorecidas: "uma coisa que eu acho importante e muito significativa pra (sic)mim, que nas Jornadas de Junho até hoje eu tive um salto, e eu compreendo como salto, mas uma mudança mesmo no tato, na compreensão, que foi a pauta do feminismo" (informação verbal). ${ }^{31}$ As questões de gênero também tensionaram o discurso de autogestão muito presente nas arenas construídas no pós-junho: "como vou entender o que uma mulher homossexual passa? Não vou. E aí se eu não tiver disposto a essa troca, a esse compartilhamento, realmente nós não temos como construir igualmente e horizontalmente em situação nenhuma" (informação verbal). ${ }^{32}$

Uma fala de uma ativista de São Paulo também é particularmente reveladora a esse respeito. ${ }^{33}$ Integrante ativa de um coletivo autonomista e de origem pobre, a entrevistada relatou o árduo percurso de aprendizados mútuos em que pautas feministas foram trabalhadas no interior do coletivo. De acordo com ela, foram muitos os conflitos internos para que, de um lado, o coletivo entendesse que a opressão de gênero era muito presente, e, de outro, para que as mulheres "de classe média compreendessem que, se o cara pisou no pé delas, isso não significava que era machista" (informação verbal). ${ }^{34}$ $\mathrm{Na}$ interseção entre classe, raça e gênero, a ativista relata um processo

31 Entrevista concedida pelo ENTREVISTADO L. Entrevista. [15 dez. 2014]. [S.I.], 2014.

32 Entrevista concedida pelo ENTREVISTADO J. Entrevista. [17 dez. 2014]. [S.I.], 2014.

33 Salientamos que as entrevistas de São Paulo não foram analisadas neste artigo e o presente relato é mobilizado apenas com vistas a levantar novos insights sobre a complexidade de gênero.

34 Anotação de declaração não gravada, feita no contexto de entrevista realizada em 20/10/2014 (mulher, 25 anos, escolaridade não declarada, cor não declarada, MPL). 
de aprendizado amplo em que os diversos atores deslocam-se e transformam-se a partir de seus conflitos.

Ao olharmos para as manifestações, há dificuldade em apontar o que são os resultados e como mensurá-los. Por vezes, busca-se uma materialidade específica, desconsiderando a dimensão processual e pedagógica que a participação das pessoas, em diferentes instâncias, produz. No que concerne à participação das mulheres nos protestos e a forma de enfrentamento aos diferentes tipos de opressão sofridos nas ruas e em instâncias de debate, compreender a vivência do desrespeito e da autonomia mostra-se fundamental. Se a justiça é, de fato, um emaranhado, são esses fios soltos que permitem a desnaturalização de questões e a luta pública. Como pontua uma das entrevistadas: "que bom que os conflitos estão aparecendo,que a gente está podendo lidar com eles, porque quando eles não apareciam eles não deixavam de existir" (informação verbal). ${ }^{35} \mathrm{~A}$ visibilidade da opressão é condição de possibilidade de seu questionamento.

\section{Considerações finais}

Este artigo buscou discutir a dimensão ambivalente de conflitos políticos, a partir de um estudo de caso focado em questões de gênero nas Jornadas de Junho de 2013 e em seus desdobramentos. Procurou-se argumentar que a luta por justiça é inerentemente paradoxal, sendo atravessada por práticas opressivas, mas também pela possibilidade de desvelamento e questionamento de tais práticas. Argumentou-se que avanços e retrocessos são inerentes a conflitos emancipatórios.

Inicialmente, o artigo discutiu como três matrizes teóricas oferecem contribuições para compreender essas ambivalências. Com a discussão sobre confronto político, no campo das teorias de movimentos sociais, assinalou-se o enraizamento social dos conflitos e a forma como lutas supostamente emancipatórias atualizam redes tácitas de significação que alicerçam práticas

35 Entrevista concedida pela ENTREVISTADA H. Entrevista. [18 nov. 2014]. [S.I.], 2014. 
opressivas. Tal abordagem também se mostrou relevante para a compreensão do modo como os processos de socialização são uma consequência intangível de lutas sociais, revelando a transformação de atores ao longo das próprias lutas. Na sequência, mobilizamos algumas ideias trabalhadas por Axel Honneth para assinalar a dimensão paradoxal de lutas por justiça, que, muitas vezes, acenam com possibilidades emancipatórias, mas atualizam formas de desrespeito. Ainda com Honneth, ressaltamos o potencial transformador do desrespeito que atua como fonte de motivação para o questionamento de injustiças e para a antecipação de padrões futuros de justiça. Por fim, com Biroli, recuperamos elementos do debate feminista sobre autonomia para explorar como fissuras na dominação podem surgir da percepção e na tematização da opressão.

Com base nessas ideias, olhamos para processos políticos desdobrados das Jornadas de Junho de 2013 com foco na questão de gênero. Partindo da premissa de que o impulso inicial da mobilização em tais processos não foram as questões de gênero, buscamos mapear a maneira como práticas de desrespeito a mulheres atravessavam os protestos e os coletivos neles envolvidos. A análise de 20 entrevistas semiestruturadas realizadas em Belo Horizonte contribuiu para a constatação de diversas práticas opressivas nessas lutas, incluindo violências contra o corpo de mulheres, o cerceamento à fala e a atuação política em espaços tidos como horizontais.

Em seguida, assinalamos para a existência de tentativas de questionamento dessas práticas desrespeitosas. Procuramos evidenciar como mulheres organizaram-se e criaram estratégias para revelar o desrespeito e alterá-lo. Seja com a organização de Frentes Feministas, seja com a realização de seminários para evidenciar as manifestações do patriarcado, seja com a elaboração de notas públicas contra assédios sexuais, mulheres trouxeram elementos de pautas feministas para o cerne do processo político aqui analisado e questionaram formas naturalizadas de opressão de gênero. 
Essa constatação da dimensão ambivalente e paradoxal de lutas por justiça contribui para o fortalecimento da ligação entre justiça e democracia. Justiça é uma construção processual. Ações, demandas e políticas voltadas à promoção de justiça portam consigo, em potência ou na prática, novas injustiças que precisam ser questionadas em uma luta com fim em aberto. Se, como propusemos neste artigo, a noção de justiça está mais próxima da de um emaranhado com fios desencontrados e descontínuos do que da de um pacote bem definido de soluções, não há outro caminho para seu fortalecimento que não a luta democrática permanente para alterar disposições sempre temporárias deste emaranhado.

\section{Referências}

ASSEMBLEIA POPULAR HORIZONTAL BELO HORIZONTE.

Nota de esclarecimento sobre os casos de violência ocorridos na ocupação da Câmara. [S.1.]: [s.n.], 2013. Disponível em: <https:// www.facebook.com/notes/assembleia-popular-horizontalbelo-horizonte/nota-de-esclarecimento-sobre-os-casos-deviol\%C3\%AAncia-ocorridos-na-ocupa\%C3\%A7\%C3\%A3o-dac\%C3\%A2ma/159369884255159>. Acesso em: 26 mar. 2015.

BIROLI, F. Agentes imperfeitas: contribuições do feminismo para a análise da relação entre autonomia, preferências e democracia. Revista Brasileira de Ciência Política, n. 9, p. 7-38, 2012. . Autonomia e desigualdade de gênero: contribuições do feminismo para a crítica democrática. Vinhedo: Editora Horizonte, 2013.

CASTELLS, M. Redes de indignação e esperança. Rio de Janeiro: Zahar, 2013.

DELLA PORTA, D.; DIANI, M. Social movements: an introduction. Oxford: Blackwell Publishing, 2006.

ELSHTAIN, J. B. Women in war.New York: Basic Books, 1987.

FERES JÚNIOR, J.; MIGUEL, L.; BARBARELA, E. A mídia impressa na cobertura das manifestações de junho. In: ENCONTRO ANUAL DA ANPOCS, 38., 2014, Caxambu. Anais... Caxambu: Anpocs, 2014. 
FRASER, N. Reenquadrando a justiça em um mundo globalizado. Lua Nova, São Paulo, n. 77, p. 11-39, 2009.

GIDDENS, A. A transformação da intimidade: sexualidade, amor e erotismo nas sociedades modernas. São Paulo: Ed. Unesp, 1993. GOHN, M. G. Novas teorias dos movimentos sociais. São Paulo: Loyola, 2014.

HARTMANN, H. The unhappy marriage of Marxism and Feminism. In: LIPPIT, V. (Ed). Radical political economy: explorations in alternative economic analysis. New York: M. E. Sharpe, 1996.

HARTMANN, M.; HONNETH, A. Paradoxes of Capitalism. Constellations, v. 14, n. 1, p. 41-58, 2006.

HONNETH, A. Luta por reconhecimento. Rio de Janeiro: Editora 34, 2003.

. Organized self-realization:someparadoxesofindividualization. European Journal of Social Theory, v. 7, n. 4, p. 463-478, 2004.

HOOKS, B. Ensinando a transgredir. São Paulo: Martins Fontes, 2013. JENSEN, M. J.; BANG, H. P. Occupy Wall Street: a new political form of movement and community? Journal of Information Technology \& Politics,v. 10, p. 441-161, 2013.

JOHANSSON-NOGUÉS, E. Gendering the Arab Spring? Rights and (in)security of Tunisian, Egyptian and Libyan women. Security Dialogue, v. 44, n. 5-6, p. 393-409, 2013.

JUDENSNAIDER, E. et al. (Org.). Vinte centavos: a luta contra o aumento. São Paulo: Veneta, 2013.

LACLAU, E.; MOUFFE, C. Hegemony and socialist strategy: towards a radical democratic politics. London; New York: Verso, 1985.

LIM, M. Clicks, cabs and coffee houses: social media and oppositional movements in Egypt, 2004-2011. Journalof Communication,v. 62, p. 231-248, 2012.

MALINI, F. et al. A viralização da revolta em redes sociais: genealogias do \#VemPraRua. In: MENDONÇA, R. F.; PEREIRA, M. A.; FILGUEIRAS, F. (Orgs.). Democracia digital: publicidade, instituições e confronto político. Belo Horizonte: Ed. UFMG, 2016. MARICATO, E. et al. Cidades rebeldes: passe livre e as manifestações que tomaram as ruas do Brasil. São Paulo: Boitempo; Carta Maior, 2013. 
MARKELL, P. Bound by recognition. Princeton: Princeton University Press, 2003.

MCADAM, D.; TARROW, S.; TILLY, C. Dynamics of contention. Cambridge: Cambridge University Press, 2004.

MELUCCI, A. Challenging codes: collective action in the information age. Cambridge: Cambridge University Press, 1996.

MENDONÇA, R. What if the forms of recognition contradict each other? The case of the struggles of people affected by leprosy in Brazil. Constellations, v. 21, p. 32-49, 2014.

MENDONÇA, R.; ERCAN, S. Deliberation and protest: strange bedfellows? Revealing the deliberative potential of 2013 protests in Brazil and Turkey. Policy Studies, v. 36, n. 3, p. 267-282, 2015. MEYER, D. How social movements matter. Contexts, v. 2. n. 4, p. 30-35, 2003.

. The politics of protest - social movements in America.

Oxford: Oxford University Press, 2007.

MIGUEL, L. F.; BIROLI, F. Caleidoscópio convexo: mulheres, política e mídia. São Paulo: Ed. Unesp, 2011.

MOGHADAM, V. What is democracy? Promises and perils of the Arab Spring. Current Sociology,v. 61, n. 4, p. 393-408, 2013.

. Modernising women and democratisation after the Arab Spring. The Journal of North African Studies, v. 19, n. 2, p. 137-142, 2014.

MPL - MOVIMENTO PASSE LIVRE. Não começou em Salvador, não vai terminar em São Paulo. In: MARICATO, E. et al. (Orgs.). Cidades rebeldes: passe livre e as manifestações que tomaram as ruas do Brasil. São Paulo: Boitempo; Carta Maior, 2013.

NOBRE, M. Imobilismo em movimento. São Paulo: Cia das Letras, 2013. NOGUEIRA, M. A. As ruas e a democracia. Rio de Janeiro: Contraponto, 2013.

ORTELLADO, P. Os protestos de junho entre o processo e o resultado. In: JUDENSNAIDER, E. et al. (Orgs.). Vinte centavos: a luta contra o aumento. São Paulo: Veneta, 2013.

PEDRO, J. Narrativas fundadoras do feminismo: poderes e conflitos (1970-1978). Revista Brasileira de História, São Paulo, v. 26, n. 52, p. 249-272, 2006. 
PEDRO, J.; WOLFF, C. (Orgs.). Gênero, feminismos e ditaduras no Cone Sul. Santa Catarina: Ed. Mulheres, 2010.

PENNEY, J.; DADAS, C. (Re)Tweeting in the service of protest: digital composition and circulation in the occupy Wall Street movement. New Media and Society, v. 16, n. 1, p. 74-90, 2014.

PHILLIPS, A. The politics of presence. Oxford: Clarendon Press, 1995. POMAR, M. Introdução: não foi um raio em céu azul. In: JUDENSNAIDER, E. et al. (Orgs.). Vinte centavos: a luta contra o aumento. São Paulo: Veneta, 2013.

RICCI, R.; ARLEY, P. Nas ruas - a outra política que emergiu em junho de 2013. Belo Horizonte: Letramento, 2014.

ROSS, K.; BYERLY, C. Women and media-international perspectives. Oxford: BlackwellPublishing, 2006.

SAFFIOTI, H. A mulher na sociedade de classes. 3. ed. São Paulo: Expressão Popular, 2013.

SARMENTO, R. Estereótipos de mulheres políticas na mídia: quadros de análise com base em entrevista de Dilma Rousseff a Patrícia Poeta. Cadernos da Escola do Legislativo, v. 15, n. 23, p. 3-21, 2013.

SARTI, C. O feminismo brasileiro desde os anos 1970: revisitando uma trajetória. Revista Estudos Feministas, Florianópolis, v. 12, n. 2. p. 35-50, 2004.

SCHERER-WARREN, I.Redes de movimento sociais. 6. ed. São Paulo: Loyola, 2014.

SREBERNY, A.; VAN ZOONEN, L. (Eds.). Gender, politics and communication. New York: Hampton Press, 2000.

TARROW, S. O poder em movimento: movimentos sociais e confronto político. Rio de Janeiro: Vozes, 2009.

TULLY, J. Struggles over recognition and distribution. Constellations, v. 7, n. 4, p. 469-482, 2000.

VAINER, C. Quando a cidade vai às ruas. In: MARICATO, E. et al.(Orgs.). Cidades rebeldes: passe livre e as manifestações que tomaram as ruas do Brasil.São Paulo: Boitempo; Carta Maior, 2013. 
WOJCIESZAK, M.; SMITH, B. Will politics be tweeted? New media use by Iranian youth in 2011. New Media \& Society, v. 16, n. 1, p. 91-109, 2014.

YOUNG, I. M. Throwing like a girl: a phenomenology of feminine body comportment motility and spatiality. Human Studies, v. 3, n. 2, p. 137-156, 1980.

. Inclusion and democracy. Oxford: Oxford University Press, 2000. 


\section{Apêndice - Características dos/as entrevistados/as ${ }^{36}$}

Entrevistada A: idade não declarada, Ensino Superior incompleto, negra, Coletivo da Educação do Campo.

Entrevistada B: 33 anos, Ensino Superior completo, "branca misturada", diversos movimentos autonomistas.

Entrevistado C: 25 anos, Ensino Superior completo, branco, PSOL.

Entrevistado E: 30 anos, Ensino Superior completo, pardo, independente.

Entrevistado F: 31 anos, Ensino Superior completo, "pardo, mulato, mestiço", Espaço Comum Luiz Estrela.

Entrevistada H: 24 anos, Ensino Superior incompleto, cor não declarada, Tarifa Zero.

Entrevistado J: 31 anos, escolaridade não declarada, "branco, preto, negro", Família de Rua.

Entrevistado L: 22 anos, escolaridade não declarada, branco, anarquista.

Entrevistada N: 24 anos, Ensino Superior incompleto, branca, Tarifa Zero.

Entrevistada O: 24 anos, Ensino Superior completo, branca, Levante Popular da Juventude.

\section{Resumo}

Este artigo discute questões de gênero durante o processo das manifestações que ocorreram no Brasil a partir de junho de 2013. Foram levantados, dentro de coletivos envolvidos em tal processo, conflitos e tensões de gênero, bem como as estratégias adotadas para o enfrentamento deles. Essas discussões estão assentadas em três matrizes teóricas: teorias dos movimentos sociais, teoria do reconhecimento honnethiana e discussão feminista sobre autonomia. O texto está ancorado em 20 entrevistas realizadas com integrantes de coletivos de Belo Horizonte dentro da pesquisa Protestos enngajamento Político. Nossos achados evidenciam a existência de opressão dentro de movimentos tidos como emancipatórios, mas assinalam o potencial transformador do desrespeito, que instiga estes coletivos a repensarem-se ao longo de suas lutas.

Palavras-chave: manifestações; gênero; justiça; feminismo.

36 A ordem dos entrevistados apresentada neste artigo não é sequencial pois segue a ordem de entrevistas da pesquisa, sendo mantida em outros textos. 


\section{Abstract}

This paper discusses gender in the process of the demonstrations that happened in June 2013 in Brazil. It analyzes tensions and gender conflicts within groups involved in this process, as well as the strategies employed to challenge these forms of oppression. The article is grounded on three theoretical perspectives: social movement theories, Honnethian theory of recognition and feminist debates about autonomy. Empirically, the article is based on 20 interviews with activists from Belo Horizonte, which are part of the research project titled Protests and Political Engagement. Our findings show the existence of oppression within movements seen as emancipatory, while also pointing out to the transformative potential of disrespect, as collective actors are challenged to reconsider themselves throughout their struggles.

Keywords: protests; gender; justice; feminism.

Recebido em 18 de janeiro de 2016.

Aprovado em10 de setembro2016. 